\title{
APOPTOSIS AS A MECHANISM FOR BURN-INDUCED GASTRIC MUCOSAL INJURY
}

\author{
Minka Hristova ${ }^{1}$, Maria Tzaneva ${ }^{2}$, Ganka Bekyarova ${ }^{1}$, Dariya Chivchibashi ${ }^{2}$ \\ ${ }^{1}$ Department of Physiology and Pathophysiology, Faculty of Medicine, \\ Medical University of Varna \\ ${ }^{2}$ Department of General and Clinical Pathology, Forensic Medicine and Deontology, \\ Faculty of Medicine, Medical University of Varna
}

\begin{abstract}
INTRODUCTION: Severe thermal burns disturb tissue homeostasis of many organs, but the exact mechanisms of gastric mucosa changes are not yet clear. Various cellular mechanisms, such as cell activation, mitochondrial dysfunction, free oxygen radicals and cytokine overproduction may be involved in this process.

AIM: The aim of this study was to assess the levels of malondialdehyde (MDA), apoptotic proteins Bax and Bcl-2 in normal gastric mucosa and to test the hypothesis that oxidative stress activation induces apoptotic processes in the stomach after experimental thermal trauma.

MATERIALS AND METHODS: Under anesthesia, the shaved rats' dorsum was exposed to $90^{\circ} \mathrm{C}$ bath for 10 $s$ to induce third-degree burn injury, involving $30 \%$ of the total body surface area. We determined the tissue level of MDA, a lipid peroxidation marker, by spectrophotometric method and the apoptosis of epithelial cells in gastric mucosa, which was immunohistochemically determined at the level of Bcl-2 and Bax in burn trauma.

RESULTS: The gastric MDA level was higher $(p<0.01)$ in the burned group compared to the control group 24 hours after thermal injury. The gastric mucosa in the treated group showed congestion, degenerative changes in the surface epithelium, focal destruction of glandular epithelium with formation of acute erosions. Bax expressed moderately in epithelial cells, predominantly in the basal parts of the gastric glands, while in the control group protein content was localized in the same region, but it was weak. Bcl-2 protein in the control group revealed nuclear expression in surface epithelium, while in the basal layer of gastric mucosa the expression was moderate and mainly cytoplasmic. In the burned group, Bcl-2 expression was more diffuse, nuclear and cytoplasmic, but cytoplasmic expression was weak.

CONCLUSION: Thermal skin trauma induces gastric mucosal injury through the activation of lipid peroxidation, increase of pro-apoptotic Bax protein expression and decrease of anti-apoptotic Bcl-2 protein expression in epithelial cells. We suggest that apoptosis is a possible mechanism for structural changes in the gastric mucosa. Scr Sci Med. 2018;50(1):25-30
\end{abstract}

Keywords: thermal trauma, gastric mucosa, apoptosis, lipid peroxidation

Address for correspondence:

Minka Hristova

Department of Physiology and Pathophysiology

Medical University of Varna

55 Marin Drinov St

9002 Varna

Bulgaria

e-mail:hristova_minka@abv.bg

Received: January 7, 2018

Accepted: March 23, 2018

\section{INTRODUCTION}

Severe thermal skin injury causes damage in many organs and systems, away from the site of exposure of the thermal agent. The digestive system is severely impaired, with dysfunction and tissue damage in all organs, including the stomach. It is known that burns lead to dilation and delayed evacuation of stomach content, formation of stress ulcers (Curling ulcers) and hemorrhages $(1,2)$. 
The exact pathogenetic mechanisms of burn-induced gastric mucosal injury are still poorly understood. The rapid onset of hypovolemia, generalized vasospasm, reduced splanchnic blood flow following thermal injury causes an imbalance between protective and aggressive factors in the gastric mucosa $(3,4)$. The production of prostaglandins and other protective factors is reduced, along with decreased antioxidant defense of the gastric mucosa $(4,5)$. Increased release of free radicals, overproduction of cytokines and other cell-derived inflammatory mediators, under conditions of reduced antioxidant defense, is probably one of the major pathogenetic mechanisms of gastric mucosal alteration in thermal injury (6-8).

The tissue damage can occur in two different ways: necrosis and apoptosis (programmed cell death (9). Apoptosis can be initiated by two main apoptotic pathways: extrinsic, receptor-mediated (death receptor) and intrinsic (mitochondrial) pathway (10). Stimulation of the mitochondrial pathway is induced by reactive oxygen species (ROS) and mitochondrial DNA damage. Pro-apoptotic Bax and anti-apoptotic Bcl-2 are members of the Bcl-2 family of proteins, which are major players in outer membrane permeabilization and translocation of cytochrome C (11).

The experimental and clinical studies show that apoptosis is a mechanism for burn-induced damage and a result of „systemic apoptotic response“ but there are not enough data for its implication in gastric mucosal injury (12).

\section{AIM}

The aim of the present study was to determine the tissue gastric level of malondialdehyde (MDA), a lipid peroxidation marker of oxidative stress, by spectrophotometric method and apoptosis of epithelial cells in gastric mucosa, which was immunohistochemically determined at the level of Bcl-2 and Bax in thermal trauma. We tested the hypothesis of burninduced apoptosis as a mechanism for cell death by increasing Bax protein expression and decreasing Bcl-2 protein expression in gastric mucosa under oxidative stress conditions.

\section{MATERIAL AND METHODS}

\section{Animals}

The experimental procedure was approved by the Home Office for Care and Use of Laboratory An- imals and performed with a strong consideration for the ethics of animal experimentation. Age-matched male Wistar rats weighing between 220 and $250 \mathrm{~g}$ fasted for $12 \mathrm{~h}$ were allowed free access to water before injury. Animals were housed in a $20^{\circ} \mathrm{C}$ and offered rat chow and water ad libitum. They were kept in dark: light cycles $(\mathrm{DL}=12: 12 \mathrm{~h})$ in individual wirebottomed cages. Thus, lights were turned off at 8:00 p.m. and turned on at 8:00 a.m. for achieving satisfactory photoperiod.

\section{Experimental Design}

For the experimental procedure, fourteen animals were randomly divided into two groups ( $n=7$ in each group) as follows: control - non-burned, nontreated (C) and vehicle-treated burned group (B). After light ether inhalation, general anesthesia was performed using thiopental (30 mg/kg i.p.). In order to accomplish $30 \%$ of third-degree burn hot boiling water $\left(90^{\circ} \mathrm{C}\right)$ was applied on the back of the animals for a period of $10 \mathrm{sec}$. For those rats, which were subjected to burn injury, $4 \mathrm{~mL}$ of physiological saline were applied intraperitoneally (i.p.) for immediate resuscitation following burn injury. No animals died within the first $24 \mathrm{~h}$ of post-burn period.

\section{Biochemical Analysis}

The stomach was gently separated from the underlying tissue and homogenized in 1:5 w/v $50 \mathrm{mM}$ phosphate buffer ( $\mathrm{pH}$ 7.4) containing $0.1 \mathrm{mM}$ EDTA at $4000 \mathrm{rpm}$ for $10 \mathrm{~min}$. The homogenate was centrifuged at $800 \mathrm{x} \mathrm{g} \mathrm{rpm}$ for $15 \mathrm{~min}$ to discard the sediment and supernatant was frozen until analysis. All the manipulations were performed at $4-8^{\circ} \mathrm{C}$. The samples were analyzed immediately after thawing.

Membrane lipid peroxidation was assayed by MDA measured by its thiobarbituric acid (TBA) reactivity of stomach homogenate using the method of Porter et al. (13). Results were determined using the extinction coefficient of MDA-TBA complex at $532 \mathrm{~nm}=1.56 \times 10^{-5} \mathrm{~cm}^{-1} \mathrm{M}^{-1}$ solution and were expressed as nmol MDA/g tissue.

\section{Paraffin Processing of Tissue}

The specimens of gastric oxyntic mucosa were fixed in $10 \%$ buffered formalin ( $\mathrm{pH} 7.2)$, dehydrated in ascending series of ethyl alcohol (70\% - 100\%) and embedded in paraffin wax. Tissue sections with $5 \mu \mathrm{m}$ thickness were stained with hematoxylin and 
Minka Hristova, Maria Tzaneva, Ganka Bekyarova et al.

eosin (H\&E) and examined using a light microscope (Olympus BH-2, Tokyo, Japan).

\section{Immunohistochemistry}

The deparaffinized and dehydrated sections (5- $\mu$ m thick) were treated with $1 \%$ hydrogen peroxide for peroxidase activity inhibition for $5 \mathrm{~min}$. Then they were rinsed in $0.1 \mathrm{M}$ phosphate buffered saline (PBS) (pH 7.4) and treated with normal goat serum for $20 \mathrm{~min}$. Subsequently, the sections were incubated with primary antibody for $24 \mathrm{~h}$ at room temperature. We used the following antibodies: Bcl-2 (N-19) and Bax (C-20) (Santa Cruz, USA) in dilution 1:50. Finally, peroxidase activity was estimated by the diaminobenzydine-tetrachloride $\mathrm{H}_{2} \mathrm{O}_{2}$-method. Negative controls were incubated with non-immune sera instead of primary antibody.

The intensity of the immunohistochemical reaction was assessed as weak, moderate and strong.

\section{Statistical Analysis}

The data were statistically analyzed using a oneway analysis of variance (ANOVA) and expressed as mean \pm SEM. The statistical significance of the difference was evaluated with the unpaired Student's $t$-test. A value of $\mathrm{p}<0.05$ was considered statistically significant. The statistical analysis was performed using the GraphPad Prism software, version 6.0.

\section{RESULTS}

\section{MDA Level in Gastric Mucosal Tissue}

The gastric MDA level was found to be higher by $51 \%(\mathrm{p}<0.01)$ in the burned group compared to the control group 24 hours after thermal injury (Fig. 1).

\section{Histological Changes of Gastric Mucosa}

Microscopic evaluation revealed no architectural changes of gastric mucosa in the control group (Fig 2. A, Aa). The gastric mucosa in the burned group showed congestion, degenerative changes in the surface epithelium, focal destruction of glandular epithelium with formation of acute erosions contained cell debris and neutrophil leukocytes (Fig 2. B, Bb).

Immunohistochemical Expression of ProApoptotic Bax Protein in Gastric Mucosa

Bax expressed weakly in epithelial cells of the contol group predominantly in the basal parts of the gastric glands (Fig. $3 \mathrm{~A}$ ), while in the burn group protein content was localized in the same region, but was moderate (Fig. 3 B).

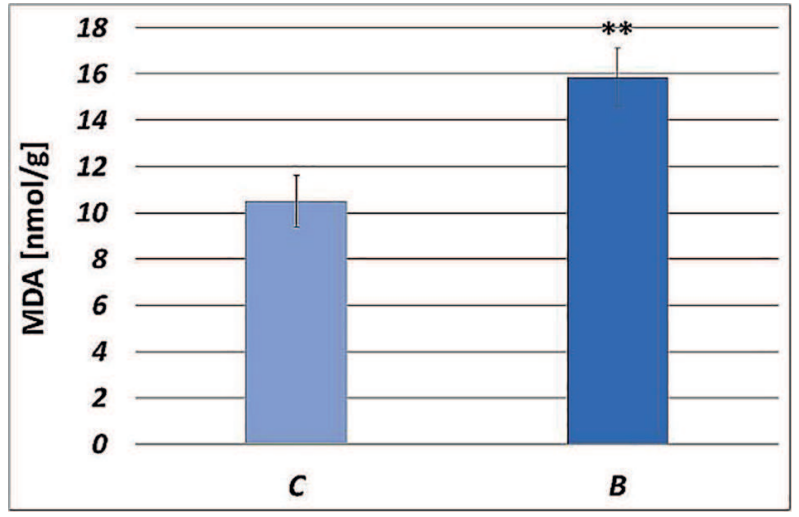

Fig. 1. MDA level in gastric mucosa after burns. (A) Control group, (B) Burned group. Results are given as mean $\pm S E M^{* *} p<0.01$ compared with control group
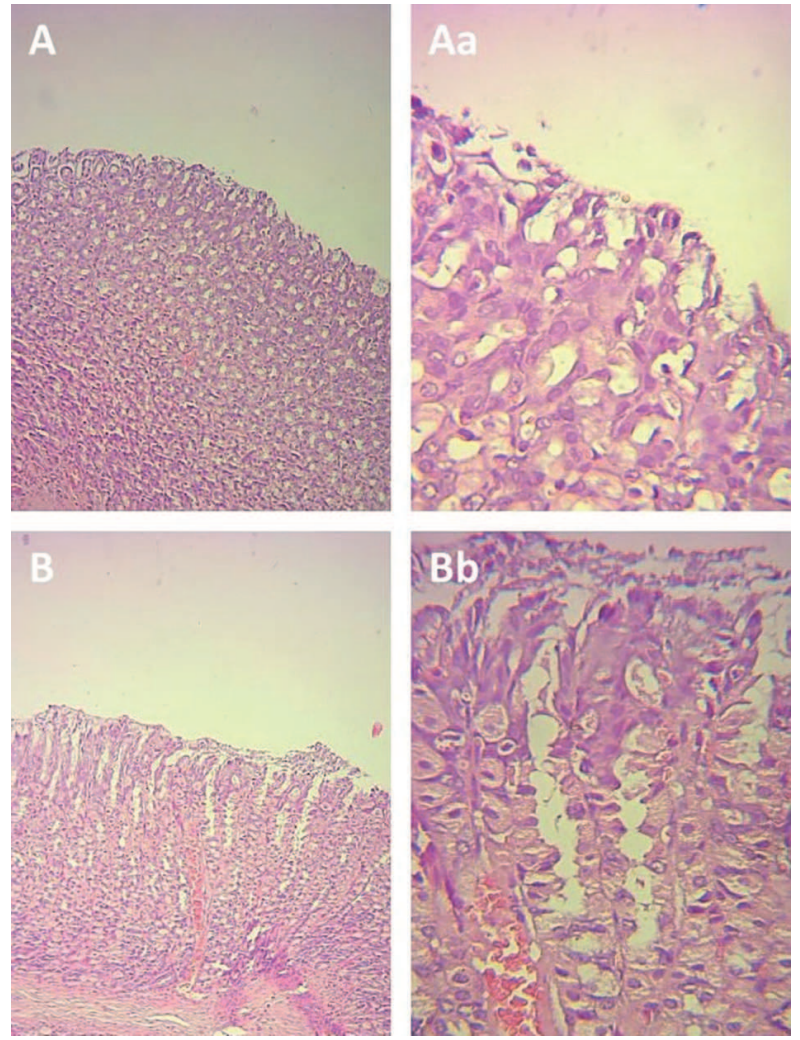

Fig. 2. Histological changes in gastric mucosa in rats. Representative data. HE staining. Original magnification 100, 200x. (A, Aa) Control group, (B, Bb) Burned group

Immunohistochemical Expression of AntiApoptotic Bcl-2 Protein in Gastric Mucosa

$\mathrm{Bcl}-2$ protein in the control group revealed nuclear expression in the surface epithelium, while in the basal layer of gastric mucosa expression was moderate and mainly cytoplasmic (Fig. 4 A). In the 

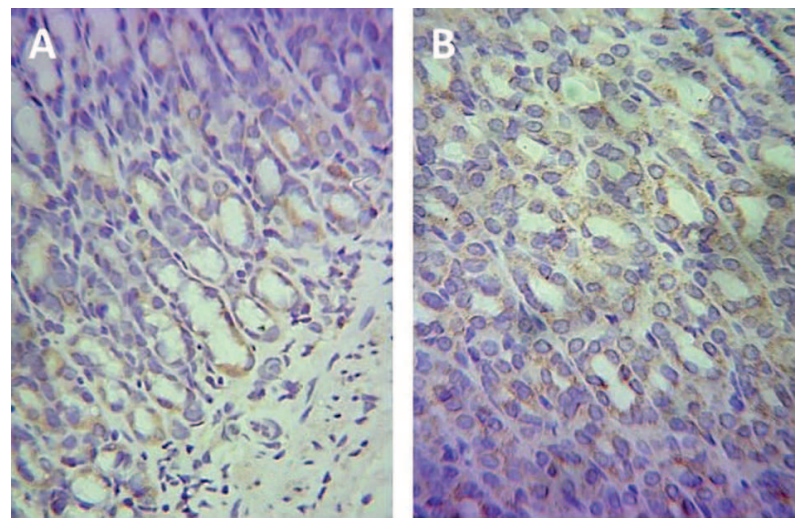

Fig. 3. Immunohistochemical expression of Bax protein in gastric mucosa after burns. (A) Control group, (B) Burned group. Representative data. Original magnification, 200.

burned group, Bcl-2 expression was more diffuse, nuclear and cytoplasmic, but cytoplasmic expression was weak (Fig 4 B).
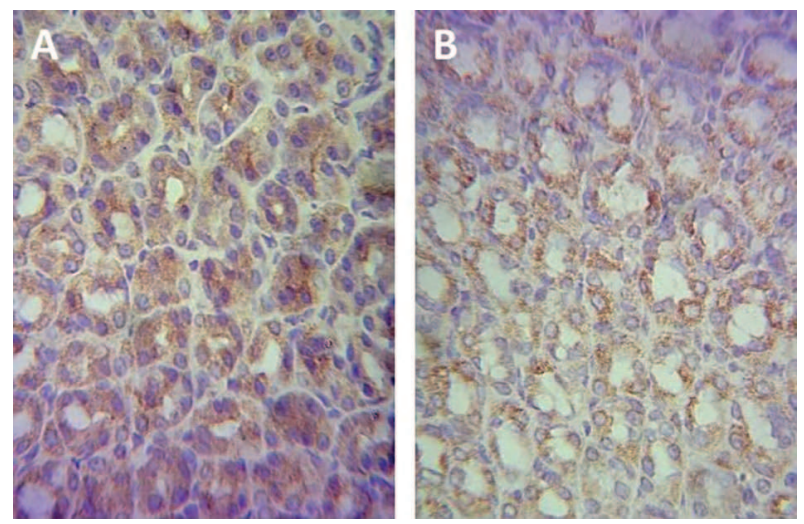

Fig. 4. Immunohistochemical expression of $B c l-2$ protein in gastric mucosa after burns. (A) Control group, (B) Burned group. Representative data. Original magnification, $200 x$

\section{DISCUSSION}

In this study, we found significantly high levels of gastric MDA, an indication of lipid peroxidation induced in burn group rats. Similar results have been obtained by other authors in experimental rat models of burns $(7,8)$. Our results showed that the high gastric MDA level in burns was associated with structural changes in gastric mucosa, such as acute erosions.

ROS and reactive nitrogen species (RNS) generation is important in for the pathogenesis of tissue damage in thermal trauma.

Increased free radicals production has been demonstrated in experimental and clinical studies of burns $(14,15)$. This is probably due to ischemia/reperfusion (I/R), xanthine oxidase activation and inflammatory mediator secretion in gastric mucosa after severe burns $(16,17)$.

We have previously reported that thermal trauma increases free radical overproduction, lipid peroxidation activation and leads to glutathione (GSH) depletion. All these contributes to oxidative gastric mucosal injury in burns (18). Other authors have reported similar results $(19,20)$.

In addition, I/R causes mitochondrial dysfunction and decreases energy production. There are disrupted mitochondrial redox balance and further increases of free radical production $(21,22)$. On the other hand, I/R induces cell inflammatory response. Activated leukocytes release ROS and pro-inflammatory mediators (TNF- $\alpha$, IL-1, IL-6) (23). Gastric myeloperoxidase (MPO) activity, an index of neutrophil infiltration, is also elevated after thermal injury (8). Similar to these studies, we also found neutrophils at the bottom of gastric erosions in the burn group. In addition, ROS and pro-inflammatory cytokines activate iNOS, an inducible form of nitric oxide synthase enzymes. iNOS is a key enzyme of "classically activated" or "killer" macrophages (M1) and contributes to NO synthesis from L-arginin (24). In support of these results in a previous study, we found increased expression of iNOS (25). Upregulated NO/iNOS production and its interaction with superoxide radicals leads to production of highly toxic peroxynitrite radical. Increased ROS/RNS formation results in oxidative stress, macromolecule alteration and possible activation of necrosis or apoptosis (26).

Apoptosis is one of the major pathways for cell death. Oxidative stress and decreased antioxidant defense contribute to both mitochondrial membrane and DNA damage. Members of the Bcl-2 family of proteins regulate the mitochondrial pathway of apoptosis (27). Bax/Bak forms oligomers on the outer mitochondrial surface and activates the caspase cascade (28). Studies have shown that programmed cell death and increased Bax protein expression play an important role gastric injuries induced by NSAID (29), ethanol $(30,31)$ and water immersion-restraint stress (32).

We established an increased level of Bax protein predominantly in the basal parts of the gas- 
Minka Hristova, Maria Tzaneva, Ganka Bekyarova et al.

tric glands in thermal trauma, while mucosal lesions were found in the superficial layer. An elevated Bax protein expression and apoptosis have been observed in hepatocytes and intestinal cells after burns $(33,34)$. It is considered that Bax protein is the major protein, which may trigger apoptosis via different mechanisms. We considered that acute erosions at 24 hours after thermal trauma are associated with reduced of anti-apoptotic protein Bcl-2 in both nuclei and cytoplasm. The decreased level of Bcl-2 protein does not provide sufficient inhibition of apoptosis, and the epithelial cells in the superficial layer acquire a pro-apoptotic phenotype and cell death occurs. We, similar to other authors, suppose that in experimental thermal trauma the balance between pro- and anti-apoptotic proteins in gastric mucosa is disrupted (35). Similarly decreased Bcl-2 protein level was found in liver and intestinal mucosa in experimental thermal trauma $(33,36)$. The increased Bax expression in the basal layer of the gastric mucosa remains unclear, because gastric mucosa does not show structural changes in this zone.

\section{CONCLUSION}

In conclusion, thermal skin trauma causes gastric mucosal injury by lipid peroxidation and the morphological changes may relate to apoptotic cell death of epithelial cells.

\section{REFERENCES}

1. Çakir B, Yeğen BC. Systemic responses to burn injury. Turk J Med Sci. 2004; 34(4): 215-26.

2. Markell KW, Renz EM, White CE, Albrecht ME, Blackbourne LH, Park MS, et al. Abdominal complications after severe burns. J Am Coll Surg. 2009;208(5):940-7. doi: 10.1016/j. jamcollsurg.2008.12.023.

3. Spirt MJ. Stress-related mucosal disease: risk factors and prophylactic therapy. Clin Ther. 2004;26(2):197-213.

4. Zhu L, Yang ZC, Li A, Cheng DC. Reduced gastric acid production in burn shock period and its significance in the prevention and treatment of acute gastric mucosal lesions. World J Gastroenterol. 2000;6(1):84-8.

5. Brzozowski T, Konturek PC, Konturek SJ, Pajdo R, Bielanski W, Brzozowska I, et al. The role of melatonin and L-tryptophan in prevention of acute gas- tric lesions induced by stress, ethanol, ischemia, and aspirin. J Pineal Res. 1997;23(2):79-89.

6. Suzuki H, Nishizawa T, Tsugawa H, Mogami S, Hibi T. Roles of oxidative stress in stomach disorders. J Clin Biochem Nutr. 2012;50(1):35-9. doi: 10.3164/jcbn.11-115SR.

7. Işeri SO, Gedik IE, Erzik C, Uslu B, Arbak S, Gedik N, et al. Oxytocin ameliorates skin damage and oxidant gastric injury in rats with thermal trauma. Burns. 2008;34(3):361-9. doi: 10.1016/j. burns.2007.03.022

8. Sehirli O, Sener E, Sener G, Cetinel S, Erzik C, Yeğen BC. Ghrelin improves burn-induced multiple organ injury by depressing neutrophil infiltration and the release of pro-inflammatory cytokines. Peptides. 2008;29(7):1231-40. doi: 10.1016/j. peptides.2008.02.012.

9. Zeiss CJ. The apoptosis-necrosis continuum: insights from genetically altered mice. Vet Pathol. 2003;40(5):481-95. doi: 10.1354/vp.40-5-481.

10. Elmore S. Apoptosis: a review of programmed cell death. Toxicol Pathol. 2007;35(4):495-516. doi: 10.1080/01926230701320337.

11. Circu ML, Aw TY. Reactive oxygen species, cellular redox systems, and apoptosis. Free Radic Biol Med. 2010;48(6):749-62. doi: 10.1016/j. freeradbiomed.2009.12.022.

12. Gravante G, Delogu D, Sconocchia G. "Systemic apoptotic response" after thermal burns. Apoptosis. 2007;12(2):259-70. doi: 10.1007/s10495-006-0621-8

13. Porter NA, Nixon JR. Isaac R. Cyclic peroxidase and thiobarbituric assay. Biochim Biophys Acta. 1976;441(3):596-9.

14. Friedl HP, Till GO, Trentz O, Ward PA. Roles of histamine, complement and xanthine oxidase in thermal injury of skin. Am J Pathol. 1989;135(1):203-17.

15. Parihar A, Parihar MS, Milner S, Bhat S. Oxidative stress and anti-oxidative mobilization in burn injury. Burns. 2008;34(1):6-17. doi: 10.1016/j. burns.2007.04.009.

16. Armutcu F, Gürel A, Hoşnuter M, Pabuçcu O, Altnyazar C. Caffeic acid phenethyl ester improves oxidative erythrocyte damage in a rat model of thermal injury. J Burn Care Rehabil. 2004;25(2):171-8.

17. Rocha J, Eduardo-Figueira M, Barateiro A, Fernandes A, Brites D, Bronze R, et al. Anti-inflammatory effect of rosmarinic acid and an extract of 
Rosmarinus officinalis in rat models of local and systemic inflammation. Basic Clin Pharmacol Toxicol. 2015;116(5):398-413. doi: 10.1111/bcpt.12335.

18. Bekyarova G, Hristova M. Uric acid, thiols and burn-induced oxidative injury of gastric mucosa in rats. Scr Sci Med. 2012; 44 (Suppl 1):31-4.

19. Sener G, Sehirli O, Velioglu Ogune A, Erean F, Erkainli G, Gedik N, et al. Propylthiouracil (PTU)induced hypothyroidism alleviates burn-induced multiple organ injury. Burns. 2006;32(6):728-36. DOI: 10.1016/j.burns.2006.01.002.

20. Kabasakal L, Sener G, Cetinel S, Contuk G, Gedik N, Yeğen BC. Burn-induced oxidative injury of the gut is ameliorated by the leukotriene receptor blocker montelukast. Prostaglandins Leukot Essent Fatty Acids. 2005;72(6):431-40. doi: 10.1016/j. plefa.2005.02.008.

21. Padfield KE, Astrakas LG, Zhang Q, Gopalan S, Dai G, Mindrinos MN, et al. Burn injury causes mitochondrial dysfunction in skeletal muscle. Proc Natl Acad Sci U S A. 2005;102(15):5368-73. doi: 10.1073/pnas.0501211102.

22. Zang QS, Maass DL, Wigginton JG, Barber RC, Martinez B, Idris AH, et al. Burn serum causes a CD14-dependent mitochondrial damage in primary cardiomyocytes. Am J Physiol Heart Circ Physiol. 2010;298(6):H1951-8. doi: 10.1152/ ajpheart.00927.2009.

23. Kalogeris T, Baines CP, Krenz M, Korthuis RJ. Cell biology of ischemia/reperfusion injury. Int Rev Cell Mol Biol. 2012;298:229-317. doi: 10.1016/ B978-0-12-394309-5.00006-7.

24. Weisser SB, McLarren KW, Kuroda E, Sly LM. Generation and characterization of murine alternatively activated macrophages. Methods Mol Biol. 2013;946:225-39. doi: 10.1007/978-1-62703-128-8_14.

25. Hristova M, Bekyarova G, Tzaneva M. Heme oxygenase 1 expression and oxidative stress - related markers in gastric mucosa in skin burns and protection with melatonin. Trakia Journal of Sciences, 2016; 4:307-13. doi:10.15547/tjs.2016.04.001.

26. Pacher P, Szabo C. Role of the peroxynitritepoly(ADP-ribose) polymerase pathway in human disease. Am J Pathol. 2008;173(1):2-13. doi: 10.2353/ ajpath.2008.080019.

27. Brunelle JK, Letai A. Control of mitochondrial apoptosis by the Bcl-2 family. J Cell Sci. 2009;122(Pt 4):437-41. doi: 10.1242/jcs.031682.
28. Rastogi R, Sinha R, Sinha RP. Apoptosis: molecular mechanisms and pathogenicity. EXCLI Journal. 2009;8:155-181.

29. Liu YH, Zhang ZB, Zheng YF, Chen HM, Yu XT, Chen XY, et al. Gastroprotective effect of andrographolide sodium bisulfite against indomethacin-induced gastric ulceration in rats. Int Immunopharmacol. 2015;26(2):384-91. doi: 10.1016/j. intimp.2015.04.025.

30. Park JH, Jang KJ, Kim CH, Lee YH, Lee SJ, Kim $\mathrm{BH}$, et al. Ganoderma lucidum pharmacopuncture for the treatment of acute gastric ulcers in rats. J Pharmacopuncture. 2014;17(3):40-9. doi: 10.3831/ KPI.2014.17.025.

31. Golbabapour S, Gwaram NS, Al-Obaidi MM, Soleimani AF, Ali HM, Abdul Majid N. Schiff base metal derivatives enhance the expression of HSP70 and suppress BAX proteins in prevention of acute gastric lesion. Biomed Res Int. 2013;2013:703626. doi: 10.1155/2013/703626.

32. Liu J, Li ZS, Wan XJ, Wang W. Expression and function of apoptosis-related genes Bcl-2/Bax and Fas/Fas L in the course of stress ulcer. Zhonghua Yi Xue Za Zhi. 2003;83(6):504-9.

33. Bekyarova G, Tzaneva M, Hristova M. Melatonin modulates the expression of Bcl-2 family proteins in liver after thermal injury in rats. Advances in Bioscience and Biotechnology. 2013, (4):41-7. doi: 10.4236/abb.2013.411A2006

34. Zhou WJ, Zhang C, Liu Y, Liu P, Ma M, Zhang SF. Influence of oxidative stress on apoptosis and expression of bax and bcl-2 of enterocytes in burn rats with delayed resuscitation on the plateau. Zhonghua Shao Shang Za Zhi. 2009;25(4):289-93.

35. Messaris E, Kekis P, Memos N, Chatzigianni E, Menenakos E, Leandros E, et al. Sepsis: prognostic role of apoptosis regulators in gastrointestinal cells. World J Surg. 2007;31(4):787-94. doi: 10.1007/ s00268-005-0742-1

36. Jeschke MG, Debroy MA, Wolf SE, Rajaraman S, Thompson JC. Burn and starvation increase programmed cell death in small bowel epithelial cells. Dig Dis Sci. 2000;45(2):415-20. 